\title{
Confirmation of "pre-plasmolysis mediated ex-osmosis hypothesis" to obtain shoot bud morphogenesis in Catharanthus roseus
}

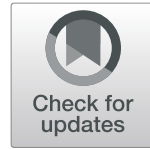

Vyoma Mistry ${ }^{1}$, Abhishek Sharma ${ }^{1,2^{*}}$ (D) and Ajay Kumar Mathur ${ }^{2}$

\begin{abstract}
The antineoplastic herb, Catharanthus roseus is a classified high-value low-volume medicinal herb which is in global attention of scientific research for modulation of its monoterpenoid indole alkaloids (MIA) pathway through genetic engineering. These secondary metabolites are generally stored in specific types of structures/compartments due to their cytotoxic nature and designated roles in plant defense response. However, their presence can hinder the genetic engineering process used to develop transgenic plants through de novo morphogenesis and regeneration of plants from cultured cells/tissues and hence, it always remained a critical impediment in transgenic research in C. roseus. The pre-plasmolysis treatment of leaf explants can help to tackle the recalcitrant nature of leaf explant and can support the direct regeneration response by ex-osmosis that minimizes the concentration of alkaloids.

Therefore, this study was performed to chase the effect of osmotic conditions on recalcitrant leaves of $C$. roseus engaged in vitro plant regeneration and hypothesis of alkaloids ex-osmosis is confirmed by HPLC analysis.
\end{abstract}

\section{Introduction}

Catharanthus roseus is an important medicinal plant due to its property to synthesize two anticancer phytomolecules monoterpenoid indole alkaloids (MIAs) vinblastine and vincristine [10, 11]. In the Indian traditional medicinal system, $C$. roseus plant parts like seeds, leaves, flowers, and roots are often used to cure diabetes, hypertension, menorrhagia, and tumor growth, whereas in the modern pharmacopeia, the plant is appreciated for two leaf-derived antineoplastic dimeric MIAs vincristine and vinblastine and root-derived antihypertensive monomeric MIAs ajmalicine and serpentine [3, 12]. However, the in planta production and availability of antineoplastic vinblastine and vincristine are highly inadequate. Also, the absence of alternative chemical synthesis has

\footnotetext{
* Correspondence: abhi19ind@gmail.com

${ }^{1}$ C. G. Bhakta Institute of Biotechnology, Uka Tarsadia University,

Gopal-Vidyanagar, Maliba Campus, Surat 394350, India

${ }^{2}$ Department of Plant Biotechnology, Central Institute of Medicinal and

Aromatic Plants (CIMAP), Council of Scientific and Industrial Research, PO CIMAP, Lucknow 226015, India
}

Springer Open

(c) The Author(s). 2021 Open Access This article is licensed under a Creative Commons Attribution 4.0 International License which permits use, sharing, adaptation, distribution and reproduction in any medium or format, as long as you give appropriate credit to the original author(s) and the source, provide a link to the Creative Commons licence, and indicate if changes were made. The images or other third party material in this article are included in the article's Creative Commons licence, unless indicated otherwise in a credit line to the material. If material is not included in the article's Creative Commons licence and your intended use is not permitted by statutory regulation or exceeds the permitted use, you will need to obtain permission directly from the copyright holder. To view a copy of this licence, visit http://creativecommons.org/licenses/by/4.0/.

enhanced their pharmaceutical industry demand and made exorbitant market cost [9].

Therefore, several plant tissue culture systems viz. suspension and hairy root cultures, elicitation, and especially genetic engineering studies were carried out on $C$. roseus to enhance the production of these pharmaceutically important molecules. However, suspension and hairy root culture systems failed to enhance antineoplastic MIAs due to their limited cellular-organ specific complexity, whereas $C$. roseus due to its recalcitrant nature was not found a very acquiescent system for whole plant genetic engineering through plant regeneration-based transgenic research [11]. Secondary metabolites are generally synthesized for plant defense response and hence may have cytotoxic nature, therefore, stored in the specified cellular sites/compartments. As major, the whole plant genetic engineering attempts were made using leaves, and being the production house of MIAs, leaves always have higher accumulated alkaloid content and may contain some unspecified compounds. These compounds probably impede the cellular dedifferentiation and redifferentiation and can be the reason for the 
recalcitrant nature of $C$. roseus leaves. Therefore, de novo morphogenesis and regeneration of plants from cultured cells/tissues has always remained a critical impediment in transgenic research in Catharanthus roseus.

Treating the leaves with pre-plasmolysis can help to confront their recalcitrant nature but can also support the direct regeneration response by ex-osmosis of stored alkaloids and toxic molecules from leaves. This applied osmotic pressure will curtail the concentration of toxic phytomolecules inside the growing leaves and/or also can influence the morphogenesis and organogenesis by quick uptake of plant growth promoters from culture media through an osmotic pull [14]. Therefore, the present study is performed to chase the effect of preplasmolysis treatment on leaf explants before culturing over the different combinations of culture media to obtain a direct shoot bud organogenesis protocol. The obtained results will help to confirm and correlate the exosmosis hypothesis through HPLC based detection of MIAs and leaf surface histological studies.

\section{Methods}

\section{Leaf explant source}

Whole leaves $(2.0-3.0 \times 1.0-1.5 \mathrm{~cm})$ from glass-house grew plants or 6-8-week-old in vitro grown multiple shoot cultures of the two C. roseus genotypes ("Dhawal" and "Nirmal" having National Gene Bank Accession Numbers (CIMAP-0859), and (CIMAP-0865), respectively) were used as explant in these experiments.

\section{Pre-plasmolysis treatment and organogenesis}

The leaf explants, before their culture over regeneration medium, were pre-plasmolyzed for $15,30,60$, and 90 min in a high osmotic (hypertonic) solution prepared by adding different concentration $(5-20 \% \mathrm{w} / \mathrm{v})$ of mannitol in the cell protoplast washing (CPW) [4] solution (Table 1). The pre-plasmolyzed leaves were given a quick wash in sterilized distilled water followed by in basal liquid MS [8] medium, blot dried, and placed horizontally with their adaxial surface in contact with the half- or full-strength woody plant medium (WPM [6];) with several combinations of BAP (1.0 to $7.5 \mathrm{mg} / \mathrm{l})$ and NAA (1.0 to $5.5 \mathrm{mg} / \mathrm{l})$. Shoot bud regeneration frequency and the rate was expressed as the mean percentage of explant responded

Table 1 Composition of cell protoplast washing (CPW) medium

\begin{tabular}{lll}
\hline S. No. & Component & Concentration (mg/l) \\
\hline 1. & $\mathrm{KH}_{2} \mathrm{PO}_{4}$ & 27.2 \\
2. & $\mathrm{KNO}_{3}$ & 100 \\
3. & $\mathrm{CaCl}_{2} \cdot 2 \mathrm{H}_{2} \mathrm{O}$ & 150 \\
4. & $\mathrm{MgSO}_{4} \cdot 7 \mathrm{H}_{2} \mathrm{O}$ & 250 \\
5. & $\mathrm{Kl}$ & 0.16 \\
6. & $\mathrm{Cu} \mathrm{SO}_{4} \cdot 5 \mathrm{H}_{2} \mathrm{O}$ & 0.025 \\
\hline
\end{tabular}

and the number of shoot buds induced per responsive explant, respectively.

\section{Alkaloids extraction and HPLC quantification}

HPLC analysis of the hypertonic solutions used for preplasmolytic treatment was carried out to trace the presence of MIAs in this pre-plasmolytic solution and to support our hypothesis of ex-osmosis of alkaloids during pre-plasmolytic treatment. For HPLC quantification, the hypertonic solutions used for pre-plasmolytic treatment were air-dried and remnants were dissolved in methanol and analyzed through high-performance liquid chromatography (HPLC) for the determination of monomeric alkaloids vindoline and catharanthine and dimeric alkaloids vinblastine and vincristine. Shimadzu ProminenceI, LC-2030 plus gradient and auto-inject HPLC system with Shimadzu RP-18e reverse-phase HPLC column was used for HPLC analysis. For mobile phase, acetonitrile to ammonium acetate (100 mM, pH 7.3) (50:50) was used and detection was done at $254 \mathrm{~nm}$.

\section{Microscopic examination of leaf epidermis}

Epidermis of control and pre-plasmolyzed leaves were peeled off using fine forceps and stained with safranine $(1 \% \mathrm{w} / \mathrm{v})$ before mounting in Canada balsam. Stained sections were viewed and photographed on a highresolution microscope (Lyka S8-APO).

\section{Experiment design and statistical analysis}

Pre-plasmolytic experiments were performed in a completely randomized design (CRD), performed three times with a minimum of 50 healthy leaves for each treatment. All data represented as a mean \pm standard deviation (SD). Statistical differences between results for preplasmolytic experiments were evaluated by two-way analysis of variance (ANOVA) and post hoc Tukey's HSD test using SPSS V. 17.0, and the values at $p<0.05$ were considered statistically significant.

\section{Results and discussion}

Leaf pre-plasmolysis and direct shoot bud organogenesis

Out of different concentrations of BAP $(1.0$ to $7.5 \mathrm{mg} / \mathrm{l})$ and NAA (1.0 to $5.5 \mathrm{mg} / \mathrm{l})$ used with half- or fullstrength woody plant medium (WPM), the full-strength WPM with $4.5 \mathrm{mg} / \mathrm{l} \mathrm{BAP}+2.5 \mathrm{mg} / \mathrm{l} \mathrm{NAA}$ was found most suitable to provide direct shoot bud formation, however, with a delayed response of 60-65 days. To further improve the shoot bud regeneration response obtained on direct regeneration medium, the effect of a pre-plasmolytic treatment on leaf explant before subjecting them to a direct regeneration experiment was evaluated in the present study. The rationale behind this approach was to facilitate the possible leaching or dilution of some of the cytotoxic and/or antimitotic 
metabolites from the explant tissue that might be hindering the in vitro de novo morphogenesis process per se. To confirm this approach, the leaves of $C$. roseus Dhawal and Nirmal genotypes were subjected to pre-plasmolysis treatment for $15,30,60$, or 90 min in $1,10,13,15$, and $20 \%(w / v)$ mannitol-fortified CPW solution before culturing them onto direct regeneration media (Table 2). In pre-plasmolytic treatment of $30 \mathrm{~min}$ in CPW, 13\% mannitol solution before culturing on shoot bud induction media provided effective results with the development of $1.46 \pm 0.09$ and $1.31 \pm 0.11$ well-organized shoot buds from leaves of Dhawal and Nirmal genotype, respectively. More than $80 \%$ of explants resulted with direct shoot bud regeneration directly from leaf without any intermediate callus phase. In the pre-plasmolysis treatment with CPW, 13\% mannitol also significantly shortened the shoot bud organogenesis period from 50-60 to 30-35 days compared to non-plasmolyzed control leaves.

For treatments with CPW, 15\% mannitol though was also effective but the regeneration frequency was lesser than in CPW, 13\% mannitol treatment. When mannitol concentration was increased to $20 \%$, the regeneration response was drastically inhibited. Treatments longer than that of 15 -min duration in $20 \%$ mannitol solution proved lethal to explant survival. Control leaf explants treated only with CPW solution (without mannitol) showed poor effect over regeneration response (12$14 \%)$. The obtained results of leaves pre-plasmolysis treatment with high mannitol concentration very badly affected the viability and organogenetic responses of leaves $[11,13]$.

HPLC analysis of the hypertonic solutions used for pre-plasmolytic treatment was carried out to check the presence of alkaloids in this hypertonic solution and to support our hypothesis of ex-osmosis of alkaloids during pre-plasmolytic treatment. HPLC analysis reviled the lower but detectable presence of monomeric alkaloids vindoline and catharanthine in hypertonic solution (13\%, $15 \%$, and $20 \%$ mannitol); however, dimeric vinblastine and vincristine were not detected (Table 3). The highest monomeric alkaloids content was observed in hypertonic solution with $20 \%$ mannitol followed by $15 \%$ and $13 \%$. Such presence of alkaloids contents in the hypertonic solutions supports the "ex-osmosis hypothesis" of alkaloids from leaves, which minimizes the concentration of

Table 2 Effect of pre-plasmolysis treatment on direct shoot bud regeneration response from leaf explants cultured on shoot regeneration media

\begin{tabular}{|c|c|c|c|c|c|c|c|}
\hline \multirow{2}{*}{$\begin{array}{l}\text { Pre-plasmolysis } \\
\text { treatment } \\
\text { (CPW: mannitol) }\end{array}$} & \multirow{2}{*}{$\begin{array}{l}\text { Duration of } \\
\text { pre-plasmolysis } \\
\text { (min) }\end{array}$} & \multicolumn{2}{|c|}{$\begin{array}{l}\% \text { of explants showing direct shoot } \\
\text { bud organogenesis mean } \pm \text { SD }\end{array}$} & \multicolumn{2}{|c|}{$\begin{array}{l}\text { Average no. of shoot } \\
\text { buds/explants } \pm \text { SD }\end{array}$} & \multicolumn{2}{|c|}{$\begin{array}{l}\text { Time required for shoot bud } \\
\text { appearance on leaf surface (days) }\end{array}$} \\
\hline & & cv. Dhawal & cv. Nirmal & cv. Dhawal & cv. Nirmal & cv. Dhawal & cv. Nirmal \\
\hline $0 \%$ & 0 & $14 \pm 1.2$ & $12 \pm 1.2$ & $1.11 \pm 0.01$ & $1.14 \pm 0.05$ & $60-65$ & $50-60$ \\
\hline \multirow[t]{4}{*}{$1 \%$} & 15 & $40 \pm 3.6$ & $17 \pm 1.6$ & $1.16 \pm 0.03$ & $1.07 \pm 0.04$ & $55-60$ & $55-60$ \\
\hline & 30 & $66 \pm 7.2$ & $27 \pm 2.4$ & $1.05 \pm 0.05$ & $1.09 \pm 0.05$ & $55-60$ & $55-60$ \\
\hline & 60 & $70 \pm 7.4$ & $37 \pm 3.4$ & $1.13 \pm 0.07$ & $1.09 \pm 0.05$ & $45-50$ & $45-50$ \\
\hline & 90 & - & - & - & - & - & - \\
\hline \multirow[t]{4}{*}{$10 \%$} & 15 & $33 \pm 3.6$ & $27 \pm 2.4$ & $1.21 \pm 0.07$ & $1.13 \pm 0.07$ & $45-50$ & $45-50$ \\
\hline & 30 & $43 \pm 4.4$ & $37 \pm 3.2$ & $1.15 \pm 0.05$ & $1.09 \pm 0.07$ & $40-45$ & $40-45$ \\
\hline & 60 & - & - & - & - & - & - \\
\hline & 90 & - & - & - & - & - & - \\
\hline \multirow[t]{4}{*}{$13 \%$} & 15 & $67 \pm 7.2$ & $27 \pm 2.4$ & $1.63 \pm 0.12$ & $1.28 \pm 0.09$ & $35-40$ & $35-40$ \\
\hline & 30 & $83 \pm 9.1$ & $43 \pm 4.6$ & $1.46 \pm 0.09$ & $1.31 \pm 0.11$ & $35-40$ & $35-40$ \\
\hline & 60 & - & - & - & - & - & - \\
\hline & 90 & - & - & - & - & - & - \\
\hline \multirow[t]{4}{*}{$15 \%$} & 15 & $60 \pm 6.8$ & $23 \pm 2.2$ & $1.16 \pm 0.07$ & $1.43 \pm 0.13$ & $30-35$ & $30-35$ \\
\hline & 30 & $77 \pm 8.2$ & $40 \pm 4.2$ & $1.26 \pm 0.09$ & $1.33 \pm 0.11$ & $30-35$ & $30-35$ \\
\hline & 60 & - & - & - & - & - & - \\
\hline & 90 & - & - & - & - & - & - \\
\hline \multirow[t]{4}{*}{$20 \%$} & 15 & & & $1.2 \pm 0.05$ & $1.0 \pm 0.03$ & $30-35$ & $30-35$ \\
\hline & 30 & - & - & - & - & - & - \\
\hline & 60 & - & - & - & - & - & - \\
\hline & 90 & - & - & - & - & - & - \\
\hline
\end{tabular}


Table 3 Alkaloids content in hypertonic pre-plasmolytic treatment solution after pre-plasmolysis of leaves

\begin{tabular}{|c|c|c|c|c|c|}
\hline \multirow{2}{*}{$\begin{array}{l}\text { Pre-plasmolysis } \\
\text { treatment } \\
\text { (CPW: mannitol) }\end{array}$} & \multirow{2}{*}{$\begin{array}{l}\text { Duration of } \\
\text { pre-plasmolysis } \\
\text { (min) }\end{array}$} & \multicolumn{2}{|l|}{ cv. Dhawal } & \multicolumn{2}{|l|}{ cv. Nirmal } \\
\hline & & $\begin{array}{l}\text { Vindoline } \\
(\mathrm{mg} / \mathrm{kg} \mathrm{wt} \pm \mathrm{SD})\end{array}$ & $\begin{array}{l}\text { Catharanthine } \\
\text { (mg/kg wt } \pm \mathrm{SD})\end{array}$ & $\begin{array}{l}\text { Vindoline } \\
\text { (mg/kg wt } \pm \mathrm{SD})\end{array}$ & $\begin{array}{l}\text { Catharanthine } \\
(\mathrm{mg} / \mathrm{kg} \text { wt } \pm \mathrm{SD})\end{array}$ \\
\hline \multirow[t]{4}{*}{$13 \%$} & 15 & ND & ND & ND & ND \\
\hline & 30 & $0.014 \pm 0.0001$ & $0.013 \pm 0.0001$ & $0.013 \pm 0.0001$ & $0.013 \pm 0.0001$ \\
\hline & 60 & $0.024 \pm 0.0002$ & $0.023 \pm 0.0003$ & $0.013 \pm 0.0002$ & $0.013 \pm 0.0002$ \\
\hline & 90 & $0.042 \pm 0.0004$ & $0.051 \pm 0.0004$ & $0.023 \pm 0.0002$ & $0.026 \pm 0.0003$ \\
\hline \multirow[t]{4}{*}{$15 \%$} & 15 & ND & ND & ND & ND \\
\hline & 30 & $0.022 \pm 0.0002$ & $0.023 \pm 0.0001$ & $0.016 \pm 0.0001$ & $0.014 \pm 0.0001$ \\
\hline & 60 & $0.040 \pm 0.0003$ & $0.032 \pm 0.0002$ & $0.022 \pm 0.0001$ & $0.014 \pm 0.0001$ \\
\hline & 90 & $0.050 \pm 0.0001$ & $0.033 \pm 0.0002$ & $0.024 \pm 0.0001$ & $0.022 \pm 0.0001$ \\
\hline \multirow[t]{4}{*}{$20 \%$} & 15 & $0.012 \pm 0.0001$ & $0.014 \pm 0.0001$ & $0.014 \pm 0.0002$ & $0.012 \pm 0.0001$ \\
\hline & 30 & $0.022 \pm 0.0002$ & $0.022 \pm 0.0002$ & $0.016 \pm 0.0001$ & $0.013 \pm 0.0001$ \\
\hline & 60 & $0.034 \pm 0.0003$ & $0.025 \pm 0.0002$ & $0.021 \pm 0.0002$ & $0.021 \pm 0.0001$ \\
\hline & 90 & $0.052 \pm 0.0004$ & $0.026 \pm 0.0003$ & $0.033 \pm 0.0003$ & $0.025 \pm 0.0002$ \\
\hline
\end{tabular}

Data expressed as the mean \pm standard deviation (SD) of the three independent biological replicates with $P<0.005 ; N D$ not detected

alkaloids in leaves thus ensuring a less toxic environment inside the growing cells of leaf explants and undergo cellular dedifferentiation and redifferentiation to facilitate direct shoot-bud organogenesis.

The microscopic examination of the leaf epidermis was carried out to understand the effect of plasmolysis on cells of leaf epidermal cells generally considered the site of organogenesis. The epidermis of C. roseus is found single-layered in all experimented leaves and the leaves contain thick-walled, irregular, and amoeboid epidermal cells bearing stomatal assembly with both anomocytic and anisocytic stomatal types (Fig. 1). Stomata are key organs responsible for gaseous exchange between the inside environment of leaves with outside air for photosynthesis along with water evaporation over transpiration [5]. The stomatal aperture inflection arises with the environmental-dependent variation in the osmotic potential of guard cells into water-fluxes and mechanical-forces that regulate the dimensions of stomatal pores [5]. Guard cells sense the osmotic pressure applied though predominant osmotically active species lie $\mathrm{K}^{+}$, malate, $\mathrm{Cl}^{-}$, sucrose, and other sugars, thus regulating the cell volume through changes in stomatal aperture $[1,7]$. The mannitol used in the present study applied a successful positive osmotic stress leading to the gradual closing of stomata (Fig. 2). However, the guard cell turgor regulation against osmotic stress is even more complicated. While picking the leaves for the experimentation the stomata were opened conceivably due to the hindered gaseous exchange from the mouth-space of the culture vessel and to maintain the equilibrium with ambient in vitro environment, the stomata remained open [2]. Verma and Mathur [13] also proposed that plasmolysis of leaves with hypertonic mannitol solution before culturing over the shoot induction media to get the support of ex-osmosis to reduce toxic metabolites inside the cells. Later the same approach was used to generate transgenic C. roseus from pre-plasmolyzed leaves undergoing dedifferentiation and redifferentiation process for de novo shoot bud organogenesis [11, 14]. This approach can have wider implications in tissue culturing of all those

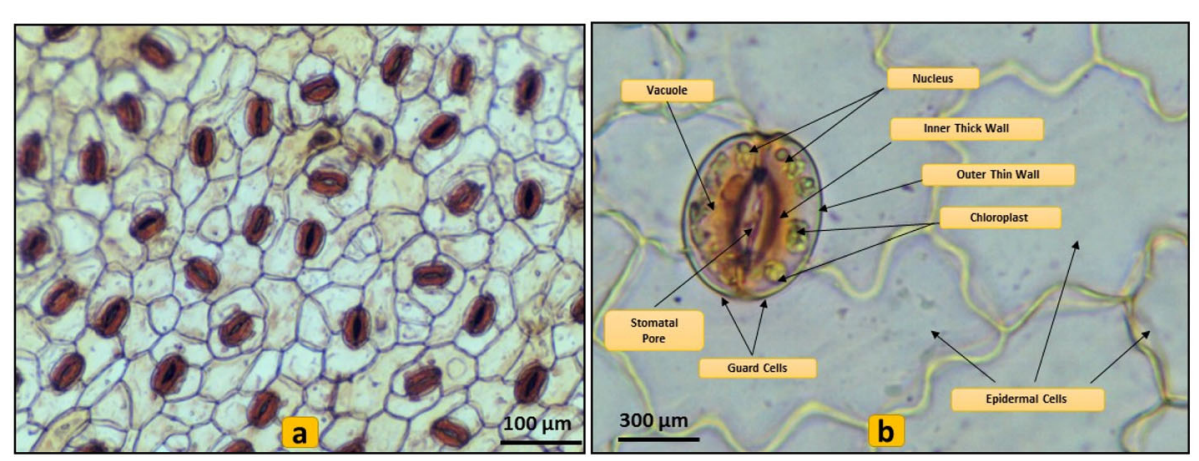

Fig. 1 Microscopic study of epidermis. Stomatal density with anomocytic and anisocytic stomata (a). Structure of stomata (b) 

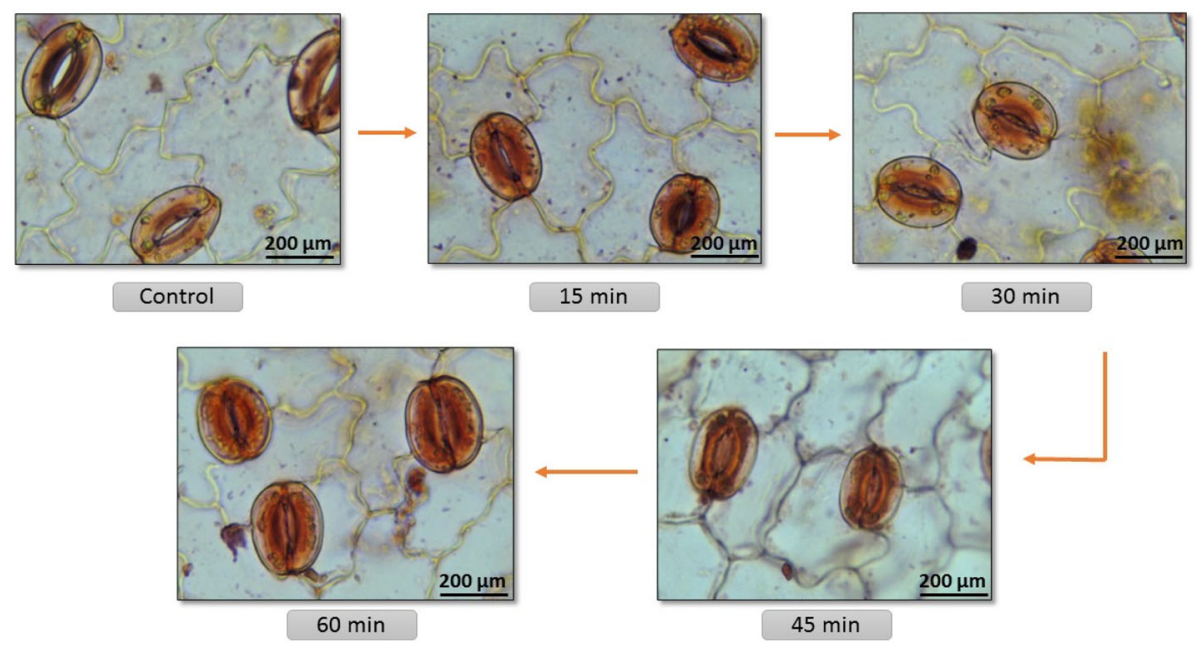

Fig. 2 Stomata under 13\% mannitol-mediated plasmolytic treatment. Open stomata (control). Closing gradually (15-30 min). Completely closed (45-60 min)

medicinal plants that are known to accumulate cytotoxic molecules in their leaves or other explants. Alternately, this treatment can also influence organogenesis by the easy and rapid uptake of plant growth regulators by leaves culturing over the shoot bud induction media through an osmotic pull [13].

\section{Conclusion}

The presented work has consolidated the observation concerning the positive influence of $13 \%(\mathrm{w} / \mathrm{v})$ mannitol CPW solution-mediated leaf explant pre-plasmolysis to obtain direct bud organogenesis that could be very useful for genetic engineering of $C$. roseus at the wholeplant level.

\section{Acknowledgements}

The authors are grateful to the INSPIRE Fellowship (IF120009), Science and Engineering Research Board, Department of Science and Technology, Government of India (grant No. SRG/2019/000130), and Research Promotion Scheme, Uka Tarsadia University (grant No. UTU/RPS/1431-5/2019), for providing financial support to their laboratory.

\section{Authors' contributions}

AKM: Conceptualized the idea and analyzed results. VM: Performed the experiment, analyzed results, and wrote manuscript. AS: Conceptualized the idea, performed the experiment, analyzed results, and wrote manuscript. All authors have read and approved the manuscript.

\section{Funding}

DST INSPIRE Fellowship to AS.

DST SERB SRG grant to AS (SRG/2019/000130).

UTU RPS grant to AS (UTU/RPS/1431-5/2019).

\section{Availability of data and materials}

Not applicable.

\section{Declarations}

Ethics approval and consent to participate Not applicable.
Consent for publication

Not applicable.

\section{Competing interests}

The authors declare no competing interests.

Received: 19 February 2021 Accepted: 19 April 2021

Published online: 07 May 2021

\section{References}

1. Assmann SM (1993) Signal transduction in guard cells. Annu Rev Cell Biol 9(1):345-375. https://doi.org/10.1146/annurev.cb.09.110193.002021

2. Costa FHS, Pasqual M, Pereira JES, de Castro EM (2009) Anatomical and physiological modifications of micropropagated 'Caipira' banana plants under natural light. Sci Agric (Piracicaba, Braz) 66:323-330

3. El-Sayed M, Verpoorte R (2007) Catharanthus terpenoid indole alkaloids: biosynthesis and regulation. Phytochem Rev 6(2-3):277-305. https://doi. org/10.1007/s11101-006-9047-8

4. Fearson et al (1973) The isolation, culture and regeneration of petunia leaf protoplast. Dev Biol 33(1):130-137. https://doi.org/10.1016/0012-1606(73)901 69-3

5. Goh CH, Hedrich R, Schreiber U (2001) Osmotic stress induces inactivation of photosynthesis in guard cell protoplasts of Vicia leaves. Plant Cell Physiol 42(10):1186-1191. https://doi.org/10.1093/pcp/pce149

6. Lloyd G, McCown BH (1980) Commercially-feasible micropropagation of mountain laurel, Kalmia atifolia by use of shoot-tip culture. Comb Proc Int Plant Prop Soc Proc 30:421-427

7. MacRobbie EAC (1995) ABA-induced ion efflux in stomatal guard cells: multiple actions of ABA inside and outside the cell. Plant J 7(4):565-576. https://doi.org/10.1046/j.1365-313X.1995.7040565.X

8. Murashige T, Skoog F (1962) A revised medium for rapid growth and bioassays with tobacco tissue cultures. Physiol Plant 15(3):473-497. https://doi.org/10.1111/j.1399-3054.1962.tb08052.x

9. Sharma A, Amin D, Sankaranarayanan A, Arora R, Mathur AK (2020) Present status of Catharanthus roseus monoterpenoid indole alkaloids engineering in homo- and hetero-logous systems. Biotechnol Lett 42(1):11-23. https://doi.org/10.1007/s10529-019-02757-4

10. Sharma A, Verma P, Mathur A, Mathur AK (2017) Genetic engineering approach using early Vinca alkaloid biosynthesis genes led to increased tryptamine and terpenoid indole alkaloids biosynthesis in differentiating cultures of Catharanthus roseus. Protoplasma 255:425-435

11. Sharma A, Verma P, Mathur A, Mathur AK (2018) Overexpression of tryptophan decarboxylase and strictosidine synthase enhanced terpenoid indole alkaloids pathway activity and antineoplastic vinblastine biosynthesis 
in Catharanthus roseus. Protoplasma 255(5):1281-1294. https://doi.org/10.1 007/s00709-018-1233-1

12. van der Heijden JDI, Snoeijer W, Hallard D, Verpoorte R (2004) The Catharanthus alkaloids: pharmacognosy and biotechnology. Curr Med Chem 11(5):607-628. https://doi.org/10.2174/0929867043455846

13. Verma P, Mathur AK (2011a) Direct shoot bud organogenesis and plant regeneration from leaf explants in Catharanthus roseus. Plant Cell Tissue Organ Cult 106:401-408

14. Verma P, Mathur AK (2011b) Agrobacterium tumefaciens-mediated transgenic plant production via direct shoot bud organogenesis from preplasmolyzed leaf explants of Catharanthus roseus. Biotechnol Lett 33(5): 1053-1060. https://doi.org/10.1007/s10529-010-0515-2

\section{Publisher's Note}

Springer Nature remains neutral with regard to jurisdictional claims in published maps and institutional affiliations.

\section{Submit your manuscript to a SpringerOpen ${ }^{\odot}$ journal and benefit from:}

- Convenient online submission

- Rigorous peer review

- Open access: articles freely available online

- High visibility within the field

- Retaining the copyright to your article

Submit your next manuscript at $\boldsymbol{\wedge}$ springeropen.com 